\title{
Comparison of Subpectoral versus Prepectoral Immediate Implant Reconstruction after Skin- and Nipple-Sparing Mastectomy in Breast Cancer Patients: A Retrospective Hospital-Based Cohort Study
}

\author{
Fabinshy Thangarajah ${ }^{a, b}$ Timo Treeter ${ }^{a}$ Barbara Krug ${ }^{c}$ Martin Hellmich $^{d}$ \\ Christian Eichler $^{a, b}$ Bettina Hanstein ${ }^{a, b}$ Peter Mallmann ${ }^{a} \quad$ Wolfram Malter $^{a, b}$ \\ a Department of Obstetrics and Gynecology, Faculty of Medicine and University Hospital, University of Cologne, Cologne, \\ ${ }^{b}$ Breast Center, University Hospital Cologne, Cologne, 'Department of Diagnostical and Interventional Radiology, University \\ of Cologne Medical School, Cologne, and Institute of Medical Statistics and Computational Biology, University of Cologne, \\ Cologne, Germany
}

\section{Keywords}

IBR $\cdot$ Breast cancer $\cdot$ Skin-sparing mastectomy $\cdot$ Nipplesparing mastectomy $\cdot$ Prepectoral $\cdot$ Subpectoral

\begin{abstract}
Introduction: Implant-based immediate breast reconstruction (IBR) is a common surgical procedure in breast cancer patients. Comparative analysis concerning the placement of implants is still lacking. Hence, we aimed to analyze pre- versus subpectoral IBR in breast cancer patients. Patients: A single-center experience with implant-based IBR following skin/nipple-sparing mastectomy was evaluated. Patient demographics, incidence of major complications, and quality of life assessed with BREAST-Q were compared between the pre- and subpectoral cohort. Results: A total of 63 patients were included in this analysis of whom 29 underwent subpectoral and 34 underwent prepectoral IBR. Median duration of surgery was prolonged in the subpectoral versus the prepectoral group (104 \pm 28 vs. $80 \pm 91$ min; $p<0.05$ ). The mean number of major complications was significantly increased in the subpectoral group $(1.41 \pm 1.76$ vs. $0.47 \pm 0.75$ per patient; $\mathrm{p}<0.05)$. Detailed analysis showed a significantly increased incidence of implant dislocation $(p<0.05)$ and a trend concerning capsular contracture $(p=0.086$, not significant) and necrosis ( $p=0.092$, not significant) in the subpectoral group. Quality of life was equal in both groups. Con-
\end{abstract}

() 2019 S. Karger AG, Basel clusion: The mean number of major complications in the subpectoral group should be considered when IBR is indicated. Prepectoral IBR seems to be a feasible alternative surgical treatment option with less major complications in selected patients.

(c) 2019 S. Karger AG, Basel

\section{Introduction}

Implant-based immediate breast reconstruction (IBR) is a common technique for post-mastectomy reconstruction [1]. Recently, the number of IBR performed has increased compared to autologous reconstruction at about $11 \%$ per year with a decline in combined implant/flap procedures [2]. One of the main reasons seems to be the better esthetic outcome achieved by IBR with skin/nipple-sparing mastectomy. Both skin- and nipple-sparing mastectomy are oncologically safe in selected patients and lead to a greater acceptance and better experience [1, 3].

For both forms of mastectomy, pre- and subpectoral positioning of the implant is possible. Patients should be selected well for these procedures. While several studies have demonstrated that subpectoral implant positioning may cause prolonged postoperative pain with subjective and objective functional impairment due to surgical mus- 
Table 1. Patient characteristics

\begin{tabular}{|c|c|c|c|c|}
\hline & $\begin{array}{l}\text { Subpectoral } \\
\text { group }\end{array}$ & $\begin{array}{l}\text { Prepectoral } \\
\text { group }\end{array}$ & Total, n & $\mathrm{p}$ \\
\hline Patients, $n$ & 29 & 34 & & \\
\hline Age, mean \pm standard deviation, years & $49.3 \pm 11.9$ & $49.9 \pm 14.8$ & 63 & 0.872 \\
\hline Body mass index, mean \pm standard deviation, $\mathrm{kg} / \mathrm{m}^{2}$ & $24.4 \pm 3.9$ & $24.7 \pm 4.6$ & 61 & 0.762 \\
\hline Smoking status, no/yes, $\mathrm{n}$ & $23 / 5$ & $25 / 9$ & 62 & 0.420 \\
\hline Diabetes mellitus, no/yes, $\mathrm{n}$ & $26 / 2$ & $33 / 1$ & 62 & 0.585 \\
\hline \multicolumn{5}{|l|}{ Pathology, $\mathrm{n}$} \\
\hline Type of tumor & & & 61 & \\
\hline Invasive/in situ & $17 / 10$ & $24 / 10$ & & \\
\hline T stage $(\mathrm{TNM})$ & & & 53 & \\
\hline Tis & 10 & 10 & & \\
\hline T1a & 2 & 3 & & \\
\hline $\mathrm{T} 1 \mathrm{~b}$ & 5 & 2 & & \\
\hline T1c & 5 & 6 & & \\
\hline $\mathrm{T} 1$ & 1 & 0 & & \\
\hline $\mathrm{T} 2$ & 2 & 5 & & \\
\hline T3 & 0 & 2 & & \\
\hline $\mathrm{N}$ stage (TNM) & & & 63 & \\
\hline Negative $(=\mathrm{N} 0)$ & 24 & 23 & & \\
\hline Positive ( $\geq$ N1) & 3 & 9 & & \\
\hline Unknown (= Nx) & 0 & 2 & & \\
\hline M stage (TNM) & & & 59 & \\
\hline M0 & 13 & 25 & & \\
\hline M1 & 0 & 0 & & \\
\hline $\mathrm{Mx}$ & 13 & 8 & & \\
\hline Estrogen receptor status & & & 58 & \\
\hline Negative/unknown/positive & $8 / 0 / 17$ & $8 / 1 / 24$ & & \\
\hline Progesterone receptor status & & & 58 & \\
\hline Negative/unknown/positive & $12 / 0 / 13$ & $10 / 0 / 23$ & & \\
\hline HER2/neu receptor status & & & 44 & \\
\hline Negative/unknown/positive & $13 / 2 / 5$ & $20 / 1 / 3$ & & \\
\hline Grading & & & 63 & \\
\hline G1 & 4 & 3 & & \\
\hline G2 & 14 & 18 & & \\
\hline G3 & 9 & 13 & & \\
\hline G4 & 0 & 0 & & \\
\hline Final resection status & & & 60 & \\
\hline R0 & 26 & 34 & & \\
\hline $\mathrm{R} 1 / 2$ & 0 & 0 & & \\
\hline \multicolumn{5}{|l|}{ Neoadjuvant therapy, $n$} \\
\hline Neoadjuvant chemo-/antibody therapy, no/yes & $25 / 4$ & $26 / 8$ & 63 & 0.327 \\
\hline Neoadjuvant endocrine therapy, no/yes & $28 / 1$ & $32 / 2$ & 63 & \\
\hline \multicolumn{5}{|l|}{ Surgery prior to current surgery, $\mathrm{n}$} \\
\hline No/yes & $16 / 13$ & $17 / 17$ & 63 & 0.682 \\
\hline Main breast surgery & & & 63 & \\
\hline \multicolumn{5}{|l|}{ Indication, $\mathrm{n}$} \\
\hline Cancer & 27 & 34 & & \\
\hline Prophylactic & 2 & 0 & & \\
\hline Surgical technique, $\mathrm{n}$ & & & & 0.402 \\
\hline Skin-sparing mastectomy & 15 & 14 & & \\
\hline Nipple-sparing mastectomy & 14 & 20 & & \\
\hline Volume of implant, mean \pm standard deviation, $\mathrm{ml}$ & $292 \pm 101$ & $293 \pm 97$ & & 0.975 \\
\hline \multicolumn{5}{|l|}{ Placement of implant, $\mathrm{n}$} \\
\hline Subpectoral & 29 & 0 & & \\
\hline Prepectoral & 0 & 34 & & \\
\hline \multicolumn{5}{|l|}{ Adjuvant therapy, $\mathrm{n}$} \\
\hline Chemo-/antibody therapy, no/yes & $25 / 4$ & $27 / 7$ & 63 & \\
\hline Endocrine therapy, no/yes & $15 / 14$ & $14 / 19$ & 62 & \\
\hline Radiation, no/yes & $28 / 1$ & $31 / 3$ & 63 & 0.618 \\
\hline
\end{tabular}


cle injury requiring physical rehabilitation [4-7], prepectoral placement of silicone implants is known to be associated with capsular contracture $[2,8]$.

Since placement of the implants in the prepectoral space appears to be a simpler alternative to subpectoral placement, it is becoming increasingly popular [9].

However, comparative studies are limited and results vary. Hence, we aim to report on an analysis of subpectoral versus prepectoral implant-based IBR after skin/nipple-sparing mastectomy in breast cancer patients.

\section{Patients and Methods}

In this retrospective study, we analyzed consecutive patients with breast cancer who underwent implant-based IBR after skinor nipple-sparing mastectomy with either pre- or subpectoral placement of the implant by experienced breast surgeons according to surgical standards.

Patients were treated in the Breast Center of the University Hospital of Cologne and underwent surgery between 2011 and 2013. Patients were followed up for 18 months.

The medical records of all patients were obtained from the comprehensive electronic hospital information system $\left(\right.$ ORBIS ${ }^{\circledR}$ OpenMed, AGFA HealthCare NV, Mortsel, Belgium) and patient records of the university hospital. The clinical and histological characteristics of each patient and each surgical procedure were also extracted from the patient records.

Postoperative follow-up included data concerning duration of hospital stay and major complications. Patients' quality of life was assessed with the BREAST-Q questionnaire.

Major complications were defined as 'loss of nipple sensation', 'postoperative bleeding with need for revision surgery', 'fistula formation with need for surgery', 'infection', 'pectoralis major problems', 'postoperative bleeding without need for revision surgery', 'necrosis', 'arm pain after hospital discharge', 'capsular contracture', 'cutaneous retraction/thin skin flap', 'implant dislocation', 'secondary wound healing disorder', and 'breast pain after hospital discharge' $[10,11]$.

Patient characteristics were described using number (percentage), mean \pm standard deviation (SD), or median (interquartile range, IQR), as appropriate. The study was approved by the local ethics committee.

All reported $p$ values (Mann-Whitney $U$ test for quantitative data or Fisher's exact test for qualitative data) are 2-sided and considered statistically significant if $<0.05$. Statistical analysis was done with the software SPSS Statistics (IBM Corp., Armonk, NY, USA).

\section{Results}

A total of 63 patients were included in this analysis. Among the study cohort, 34 patients underwent a prepectoral and 29 a subpectoral immediate IBR after skin- or nipple-sparing mastectomy due to breast cancer. 2 patients received immediate IBR after a prophylactic skinor nipple-sparing mastectomy with a history of breast cancer in the contralateral breast.
Table 2. Analysis of preoperative mammograms according to the guidelines of Rancati et al. [12]

\begin{tabular}{lll}
\hline $\begin{array}{l}\text { Subcutaneous tissue } \\
\text { thickness }\end{array}$ & $\begin{array}{l}\text { Subpectoral group, } \\
\%\end{array}$ & $\begin{array}{l}\text { Prepectoral group, } \\
\%\end{array}$ \\
\hline Type $1(\leq 1 \mathrm{~cm})$ & 25.0 & 22.2 \\
Type 2 $(>1-2 \mathrm{~cm})$ & 58.3 & 37.0 \\
Type $3(\geq 2 \mathrm{~cm})$ & 16.7 & 40.7 \\
\hline
\end{tabular}

Patient characteristics are summarized in table 1. Concerning age, body mass index, smoking status, and diabetes mellitus, there were no significant differences between both cohorts. Within group 1 (subpectoral reconstruction), 15 patients underwent a skin-sparing mastectomy whereas 14 patients underwent a nipple-sparing mastectomy. In group 2 (prepectoral reconstruction), 14 patients underwent a skin-sparing mastectomy whereas 20 patients underwent a nipple-sparing mastectomy. The mean volume of implant used was $292( \pm 101) \mathrm{ml}$ in the subpectoral group versus 293 $( \pm 97) \mathrm{ml}$ in the prepectoral group $(\mathrm{p}=0.975)$.

The surgical procedure was significantly prolonged in the subpectoral versus the prepectoral group (104 $\pm 28 \mathrm{vs.}$ $80 \pm 91$ min; $p<0.05)$. No significant differences were noted concerning the duration of hospital stay $(\mathrm{p}=0.111)$. The general major complication rate was increased at $51.7 \%(\mathrm{n}=15)$ in the subpectoral group compared to $35.3 \%(\mathrm{n}=12)$ in the prepectoral group $(\mathrm{p}=0.189)$.

Analysis of the preoperative mammograms according to the guidelines of Rancati et al. [12] showed that $40.7 \%$ of patients with a prepectoral IBR and $16.7 \%$ of patients with a subpectoral IBR had a subcutaneous tissue thickness of more than $2 \mathrm{~cm}$ (type 3) (table 2).

A detailed analysis showed that the mean number of major complications per patient was significantly higher with 1.41 in the subpectoral and 0.47 in the prepectoral group ( $\mathrm{p}<0.05)$. Among the major complications noted, necrosis ( $p=0.092$, not significant (ns)) and capsular contracture $(\mathrm{p}=0.086, \mathrm{~ns})$ showed a trend in favor of prepectoral reconstruction. Implant dislocation was significantly more frequent in the subpectoral group $(\mathrm{p}<0.05)$ (fig. 1 ).

Within the cohort, $13(20.6 \%)$ patients underwent surgery to remove the implant $(724.1 \%)$ in the subpectoral and $6(17.6 \%)$ in the prepectoral group; $\mathrm{p}=0.550)$.

Quality of life was assessed with the Breast-Q questionnaire. Our results showed no significant differences in quality of life between both groups (table 3).

\section{Discussion}

In this retrospective study, we analyzed 63 patients with IBR after skin- or nipple-sparing mastectomy. Overall, 29 patients underwent subpectoral IBR, 34 patients 
Table 3. Quality of life assessment

\begin{tabular}{lllll}
\hline & & Subpectoral group & Prepectoral group & $\mathrm{p}$ \\
\hline 1 & Satisfaction with breast (scale 1-4) $^{\mathrm{a}}$ & $3.0 \pm 0.75$ & $3.4 \pm 0.53$ & 0.227 \\
2 & Satisfaction with the implant (scale 1-4) $^{\mathrm{a}}$ & $3.2 \pm 0.8$ & $3.3 \pm 0.98$ & 0.766 \\
3 & Satisfaction with outcome (scale 1-3) $^{\mathrm{a}}$ & $2.6 \pm 0.5$ & $2.7 \pm 0.4$ & 1.0 \\
4 & Psychosocial well-being (scale 1-5) $^{\mathrm{a}}$ & $4.5 \pm 0.5$ & $4.4 \pm 0.7$ & 0.920 \\
5 & Sexual well-being (scale) $^{\mathrm{a}}$ & $3.7 \pm 0.9$ & $3.7 \pm 1.1$ & 0.967 \\
6 & Physical well-being (scale 1-5) $^{\mathrm{b}}$ & $1.9 \pm 0.8$ & $1.9 \pm 0.7$ & 0.943 \\
\hline
\end{tabular}

${ }^{\text {a}}$ Higher scores reflect a better outcome.

${ }^{b}$ Lower scores reflect a better outcome.

Fig. 1. Detailed analysis of major complications (absolute number, $\mathrm{p}$ values).

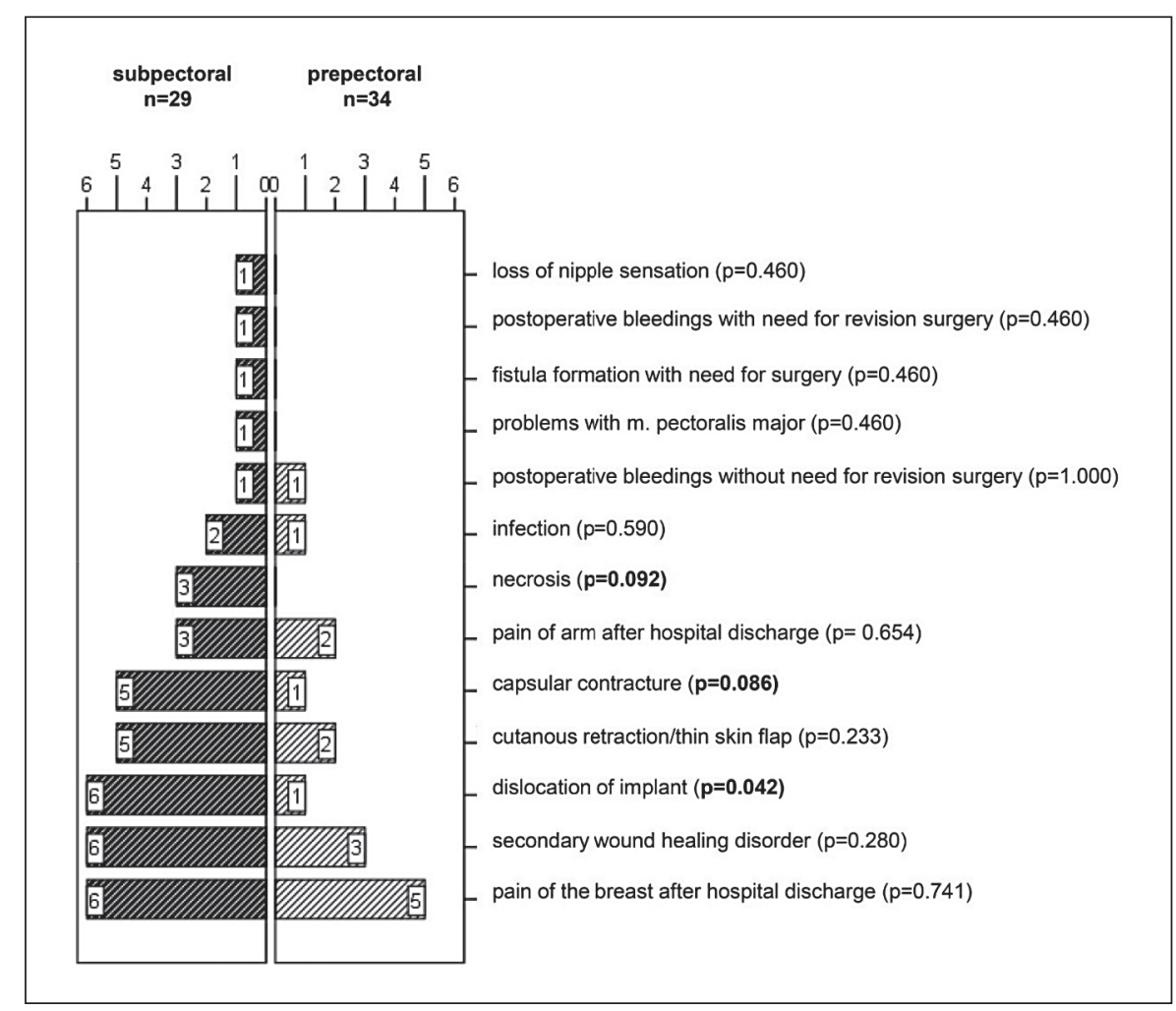

underwent prepectoral IBR. Studies that compare the clinical outcome of subpectoral versus prepectoral IBR patients are limited. The aim of this analysis was to examine the incidence of major complication as well as quality of life according to the positioning of the implant. When comparing the duration of hospitalization between both groups, we were unable to detect any differences, which is in line with previously published studies [13].

As we already know from other published data, major complication rates in IBR differ between studies. While Salgarello et al. [14] reported a rate of $8.3 \%$ of major complications with loss of implant, Eltahir et al. [15] showed a complication rate of $15.7 \%$ in the cohort of patients with IBR. Both studies included patients with both subpectoral and epipectoral IBR. In further published studies in which subpectoral reconstruction was analyzed, complication rates varied between $<10 \%[16,17], 10-20 \%$ [18-21] and $>20 \%$ [22-26].

However, one of the few comparative analyses of prepectoral versus subpectoral implant placement after conservative mastectomy showed no significant differences in complication rates [16]. In contrast to the previously mentioned studies, Bernini et al. [17] reported a lower implant exchange rate and a decreased Baker grade III/IV capsular contracture rate but a higher rate of implant loss in the prepectoral group.

Certainly, the definition of major complications seems to have an influence on the detected rate. In our cohort, we were able to show that the mean number of major complications was significantly increased in the subpec- 
Table 4. Advantages/disadvantages of prepectoral reconstruction

\begin{tabular}{|c|c|c|c|c|}
\hline Author & Year & $\begin{array}{l}\text { Subpectoral } \\
\text { group, } \mathrm{n}\end{array}$ & $\begin{array}{l}\text { Prepectoral group, } \\
\mathrm{n}\end{array}$ & Advantages and disadvantages of prepectoral reconstruction \\
\hline Bernini et al. [17] & 2015 & 35 & 34 & $\begin{array}{l}\text { lower implant exchange rate ( } 0 \text { vs. } 12 \%) \\
\text { decreased Baker grade III/IV capsular contracture ( } 0 \text { vs. } 12 \%) \\
\text { superior esthetic outcome (objectively and subjectively) } \\
\text { higher implant loss ( } 5.1 \text { vs. } 0 \%)\end{array}$ \\
\hline Casella et al. [16] & 2014 & 39 & 34 & no significant difference in complication rate \\
\hline Current analysis & & 29 & 34 & $\begin{array}{l}\text { significantly higher mean complication rate in subpectoral } \\
\text { group }(\mathrm{p}=0.042) \\
\text { higher rates of implant dislocation in subpectoral group }(\mathrm{p}= \\
0.042) \\
\text { trend toward decreased rate of capsular contracture }(\mathrm{p}= \\
0.086, \text { not significant) and necrosis }(\mathrm{p}=0.092 \text {, not signifi- } \\
\text { cant) in prepectoral group }\end{array}$ \\
\hline
\end{tabular}

toral group $(\mathrm{p}<0.05)$. Furthermore, a detailed analysis showed a significantly increased incidence of implant dislocation $(\mathrm{p}<0.05)$. Although capsular contracture is known to be a typical complication of prepectoral reconstruction [27], the current analysis showed a trend toward capsular contracture $(\mathrm{p}=0.086, \mathrm{~ns})$ and necrosis $(\mathrm{p}=$ 0.092 , ns) in the subpectoral group. Nonetheless it has to be stressed that these results were not statistically significant. Table 4 shows all discussed data and gives an overview of the various studies.

In modern breast cancer surgery, quality of life questionnaires have become an important tool for the evaluation of surgical results. 2 studies by Baker et al. [13] and Walia et al. [28] analyzed the different groups via Breast$\mathrm{Q}$ which evaluates satisfaction and quality of life. Baker et al. [13] examined short-term outcomes of subpectoral and prepectoral IBR. There was no significant difference in the mean $\mathrm{Q}$ score $(\mathrm{p}=0.81)$ between the groups. Walia et al. [28] compared quality of life in patients with prepectoral versus subpectoral tissue expander placement and came to the conclusion that Breast-Q scores were not significantly different between study groups. This is in accordance with the results of the present study since we found no significant differences in both the quality of life and the satisfaction domains.

\section{Conclusion}

Although the mean number of complications is significantly higher in the subpectoral group, this does not seem to have an impact on quality of life or patient satisfaction. This should be taken into consideration when implant-based IBR is indicated.

\section{Disclosure Statement}

The authors have no conflict of interest to declare.

\section{References}

1 Sbitany H, Piper M, Lentz R: Prepectora breast reconstruction: a safe alternative to submuscular prosthetic reconstruction following nipple-sparing mastectomy. Plast Reconstr Surg 2017;140:432-443.

$\checkmark 2$ Tasoulis M-K, Iqbal FM, Cawthorn S, et al: Subcutaneous implant breast reconstruction: time to reconsider? Eur J Surg Oncol 2017;43: 1636-1646.

3 Hammond DC: Commentary on: Prepectoral revision breast reconstruction for treatment of implant-associated animation deformity: a review of 102 reconstructions. Aesthetic Surg J 2018;38:527-528.
Cattelani L, Polotto S, Arcuri MF, et al: Onestep prepectoral breast reconstruction with dermal matrix-covered implant compared to submuscular implantation: functional and cost evaluation. Clin Breast Cancer 2018; 18:e703-e711.

5 Shamley D, Lascurain-Aguirrebeña I, Oskrochi R, Srinaganathan R: Shoulder morbidity after treatment for breast cancer is bilateral and greater after mastectomy. Acta Oncol 2012;51:1045-1053.

-6 Stubblefield MD, Custodio CM: Upper-extremity pain disorders in breast cancer. Arch Phys Med Rehabil 2006;87(3 suppl 1):S96-99.
De Haan A, Toor A, Hage JJ, et al: Function of the pectoralis major muscle after combined skin-sparing mastectomy and immediate reconstruction by subpectoral implantation of a prosthesis. Ann Plast Surg 2007;59:605-610.

8 Slade CL: Subcutaneous mastectomy: acute complications and long-term follow-up. Plast Reconstr Surg 1984;73:84-88.

-9 Sigalove S, Maxwell GP, Sigalove NM, et al: Prepectoral implant-based breast reconstruction: rationale, indications, and preliminary results. Plast Reconstr Surg 2017;139:287294. 
10 Eichler C, Vogt N, Brunnert K, et al: A headto-head comparison between SurgiMend and Epiflex in 127 breast reconstructions. Plast Reconstr Surgery Glob Open 2015;3:e439.

11 Eichler C, Efremova J, Brunnert K, et al: A head to head comparison between SurgiMend ${ }^{\circledR}$ - fetal bovine acellular dermal matrix and Tutomesh ${ }^{\circledR}$ - a bovine pericardium collagen membrane in breast reconstruction in 45 cases. In Vivo 2017;31:677-682.

12 Rancati AO, Angrigiani CH, Hammond DC, et al: Direct to implant reconstruction in nipple sparing mastectomy. Plast Reconstr Surg Glob Open 2017;5:e1369.

13 Baker BG, Irri R, MacCallum V, et al: A prospective comparison of short-term outcomes of subpectoral and prepectoral Stratticebased immediate breast reconstruction. Plast Reconstr Surg 2018;141:1077-1084.

14 Salgarello M, Rochira D, Barone-Adesi L, Farallo E: Immediate breast reconstruction after skin- or nipple-sparing mastectomy for previously augmented patients: a personal technique. Aesthetic Plast Surg 2012;36:313-322.

$>15$ Eltahir Y, Werners LLCH, Dreise MM, et al: Quality-of-life outcomes between mastectomy alone and breast reconstruction. Plast Reconstr Surg 2013;132:201e-209e.

16 Casella D, Bernini M, Bencini L, et al: TiLoop ${ }^{\circledR}$ Bra mesh used for immediate breast reconstruction: comparison of retropectoral and subcutaneous implant placement in a prospective single-institution series. Eur J Plast Surg 2014;37:599-604.
17 Bernini M, Calabrese C, Cecconi L, et al: Subcutaneous direct-to-implant breast reconstruction: surgical, functional, and aesthetic results after long-term follow-up. Plast Reconstr Surgery Glob Open 2015;3:e574.

18 Nair A, Jaleel S, Abbott N, et al: Skin-reducing mastectomy with immediate implant reconstruction as an indispensable tool in the provision of oncoplastic breast services. Ann Surg Oncol 2010;17:2480-2485.

19 Bayram Y, Kulahci Y, Irgil C, et al: Skin-reducing subcutaneous mastectomy using a dermal barrier flap and immediate breast reconstruction with an implant: a new surgical design for reconstruction of early-stage breast cancer. Aesthetic Plast Surg 2010;34:71-77.

20 Salgarello M, Barone-Adesi L, Terribile D, Masetti R: Update on one-stage immediate breast reconstruction with definitive prosthesis after sparing mastectomies. Breast 2011; 20:7-14

21 Siggelkow W, Lübbe K, Gade J, et al: Skin-reducing mastectomy with primary implant reconstruction. Geburtshilfe Frauenheilkd 2012;72:616-621.

22 Salgarello M, Visconti G, Barone-Adesi L: Nipple-sparing mastectomy with immediate implant reconstruction: cosmetic outcomes and technical refinements. Plast Reconstr Surg 2010;126:1460-1471.
23 Salgarello M, Visconti G, Barone-Adesi L, et al: Inverted $\mathrm{T}$ skin-reducing mastectomy and one-stage immediate implant reconstruction; in Shiffman MA (ed): Breast Reconstruction. Cham, Springer International Publishing, 2016, pp 511-522.

24 Nava MB, Ottolenghi J, Pennati A, et al: Skin/ nipple sparing mastectomies and implantbased breast reconstruction in patients with large and ptotic breast: oncological and reconstructive results. Breast 2012;21:267-271.

25 Dieterich M, Paepke S, Zwiefel K, et al: Implant-based breast reconstruction using a titanium-coated polypropylene mesh (TiLOOP Bra). Plast Reconstr Surg 2013;132:8e$19 \mathrm{e}$

26 Li X-R, Zhang Y-J, Wang J-D, et al: Application of immediate breast reconstruction with silicon prosthetic implantation following bilateral mammary gland excision in treatment of young patients with early breast cancer. J Thorac Dis 2013;5:278-282.

27 Gruber RP, Kahn RA, Lash H, et al: Breast reconstruction following mastectomy. Plast Reconstr Surg 1981;67:312-317.

28 Walia GS, Aston J, Bello R, et al: Prepectoral versus subpectoral tissue expander placement: a clinical and quality of life outcomes study. Plast Reconstr Surg Glob Open 2018; 6:e1731. 